status as trusted messengers creates favorable conditions for them to participate in non-partisan civic engagement.

Objectives To provide the background, tools, and support necessary for healthcare providers to address the social drivers of poor health by asking patients about their voter registration status.

Methods

- Vot-ER developed the Healthy Democracy Kit (HDK) in 2020 to adapt to the COVID pandemic's added barriers to traditional voter registration

- Health care workers and medical students were recruited via institutional and professional listservs

- Participants were prompted to watch an instructional video emphasizing that all conversations about voter registration must be nonpartisan, voluntary, and sensitive to voter eligibility requirements

Results

- Over 500 hospitals and clinics plus 25,000 healthcare providers use Vot-ER's tools

- 240+ organizations celebrate August as Civic Health Month

- Surveyed providers report increased knowledge of links between civic participation and health, improved well-being, and greater civic engagement

Conclusions Vot-ER's work over the past 18 months serves as a "proof of concept" that hospitals/clinics are ready to take on the role they're authorized to have under the 1993 National Voter Registration Act.

\section{GETTING IT RIGHT, RIGHT NOW, WHILE BUILDING SERVICES READY FOR FUTURE HEALTH NEEDS OF POPULATIONS}

${ }^{1}$ Diana Beveridge, ${ }^{2}$ Susan Hannah, ${ }^{3}$ Robert Kahn, ${ }^{4}$ Anette Nilsson. ${ }^{1}$ Scottish Government; ${ }^{2}$ Institute for Healthcare Improvement; ${ }^{3}$ Cincinnati Children's Hospital; ${ }^{4}$ Region Jonkoping County

10.1136/bmjoq-2021-|HI.11
Background Improving wellbeing outcomes of children has been a joint focus of work for three of IHI's strategic partners in recent years. They are benefitting from collaborating to support the acceleration of work that they have in common and working to close the equity related gap for children and young people in each of their localities. Although each locality is unique, these partners have found the collaboration of learning powerful for each context, and that they have more in common than sets them apart.

Objectives These large scale efforts are ambitious and focused; identifying the children who require support; identifying interventions that will deliver improved outcomes; working collaboratively across sectors and professional groups to provide services that work for the community; and applying a rigorous improvement method to support implementation of change.

Methods Service redesign approaches; co-production with children and community members; multi - disciplinary working across boundaries; the science of improvement to test, measure and implement changes.

Results Achieving high impact results at scale is the ambition of these partners, however, with the knowledge that population health outcomes are generational and can take many years to realise their full potential; these 3 partners describe impactful work on localities with smaller groups, iteratively learning for scalable work. In early years development, in schools and community centers, qualitative and quantitative data describes the journey that these partners are travelling (figures 1-5). It is a story of improvement science in practice and service redesign modelling with children and young people at the center of all they do.

Conclusions These ambitious Strategic Partners have benefitted from a collaborative and virtual learning environment where the exploration and sharing of methods, theories, evidence and practice has supported this global enquiry into child wellbeing, equity and equality issues for disadvantaged communities, and the application of improvement science methods to accelerate change today and for the future.

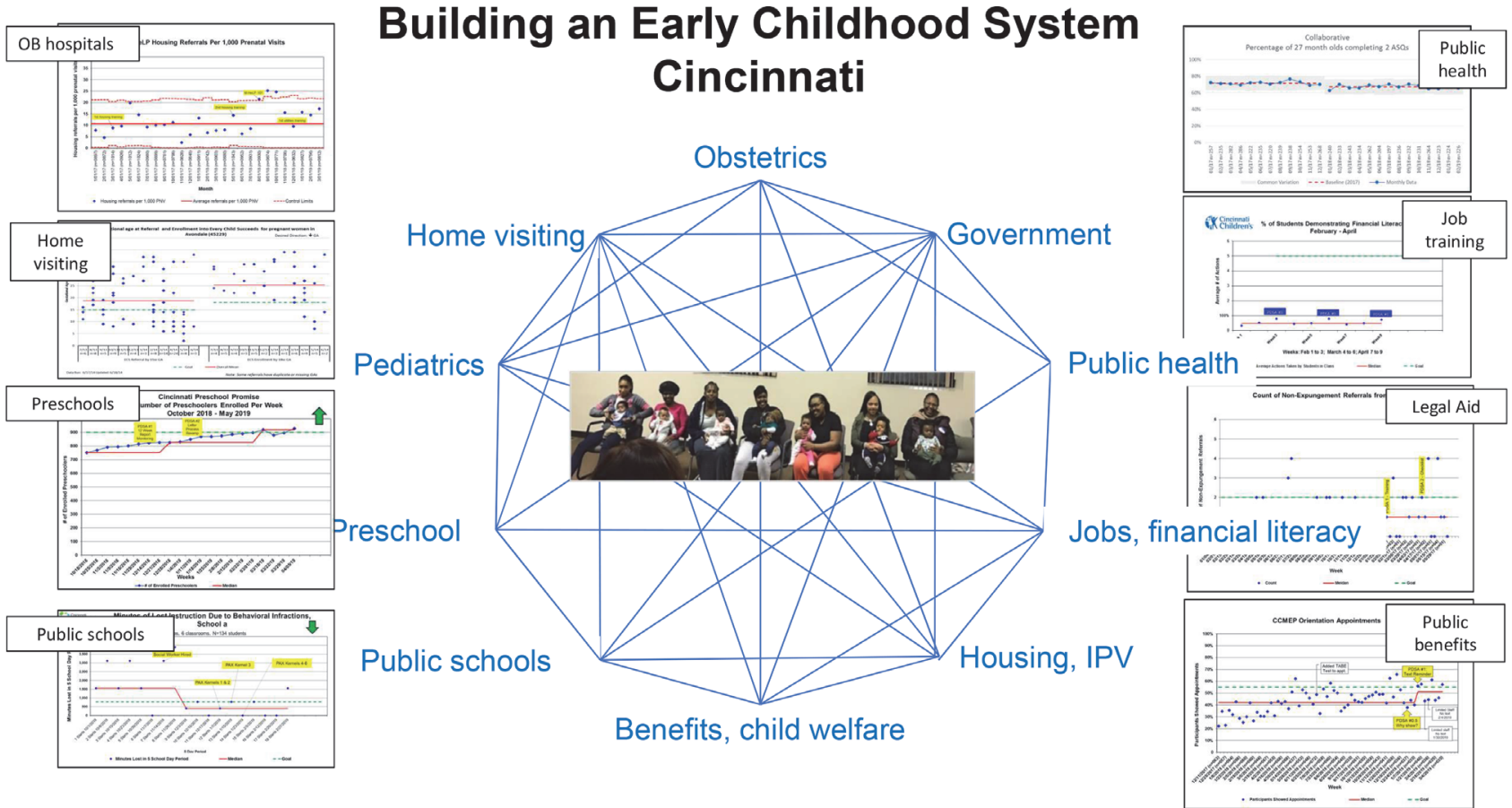


Vision: Jönköping children's health - the best place to stay, live and grow up
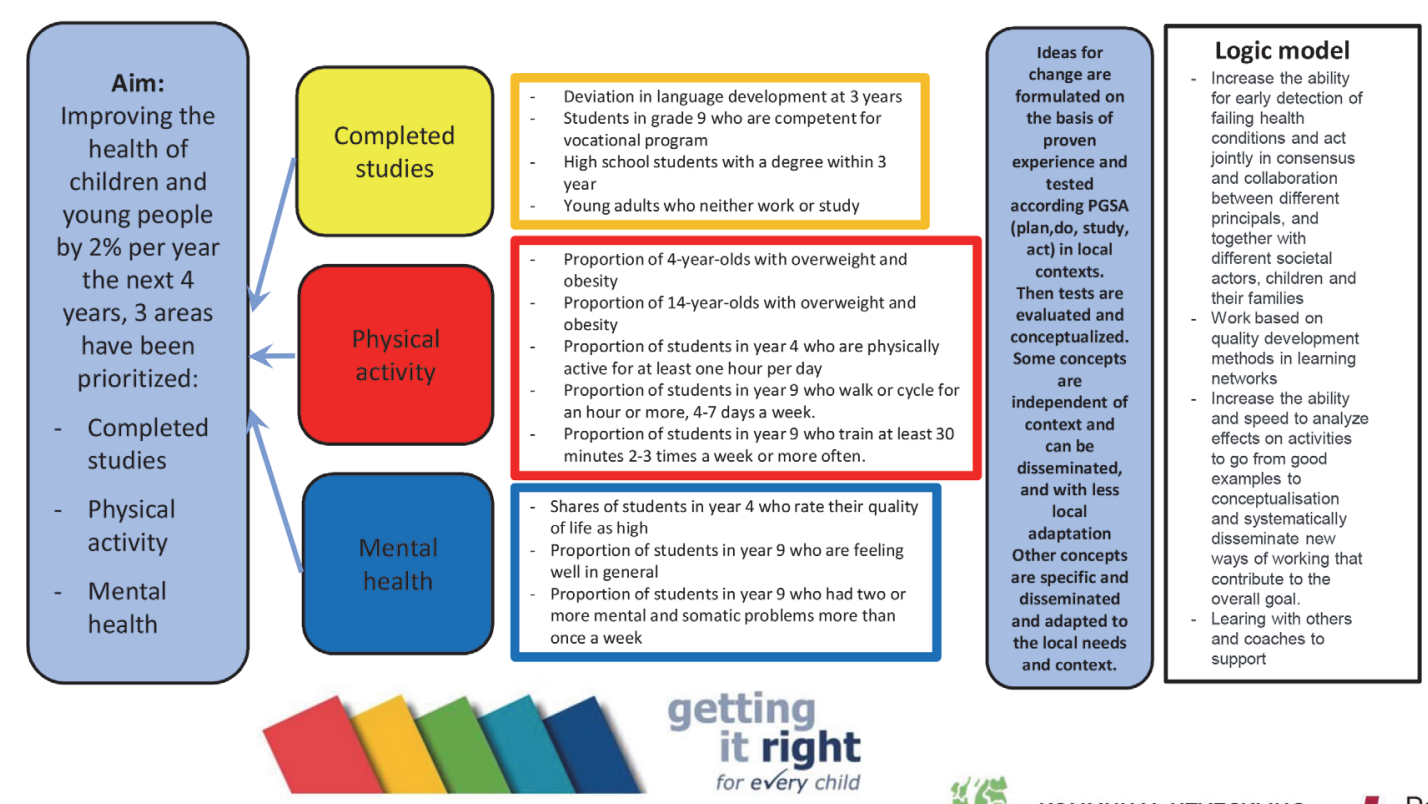

\section{getting \\ it right}

KOMMUNAL UTVECKLING JÖNKÖPINGS LÄN

Region

Jönköpings län

\section{Abstract 11 Figure 2}

Meeting places - working together, school, community, healthcare practitioners in both physical and digital forums during the pandemic
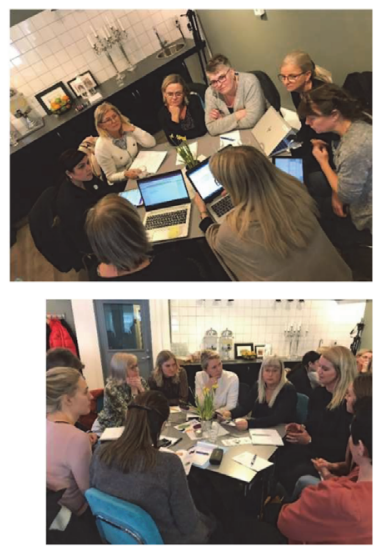

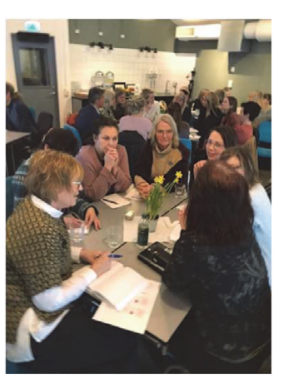

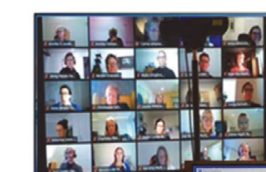

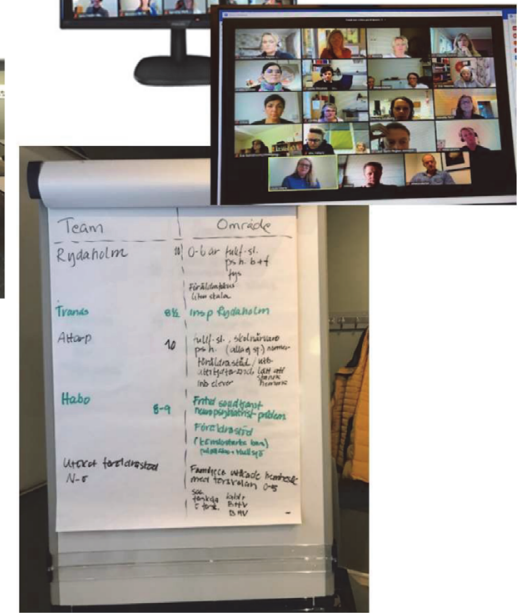

KOMMUNAL UTVECKLING JÖNKÖPINGS LÄN 


\section{Newsletters to share learning and build engagement}

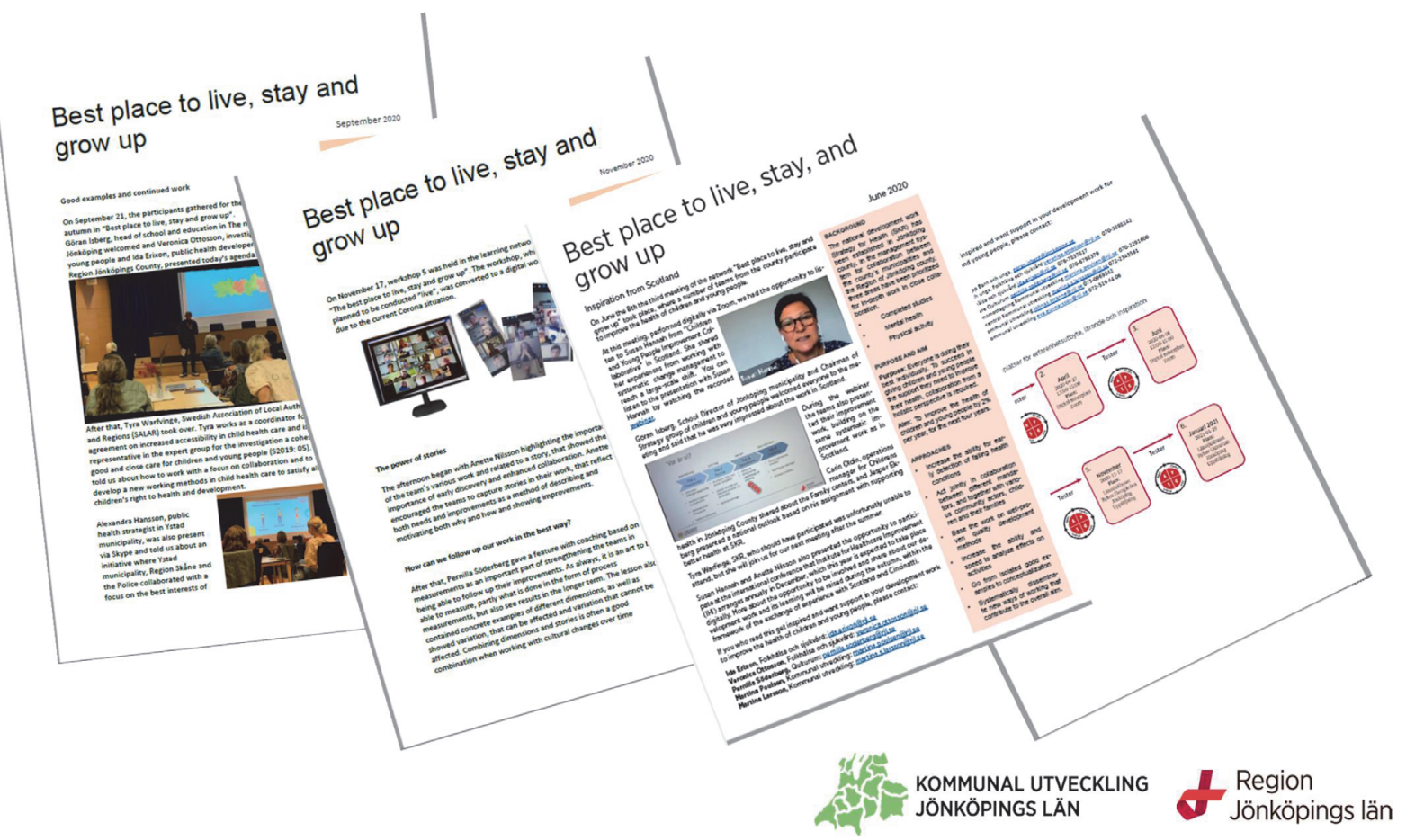

Abstract 11 Figure 4

Service Design

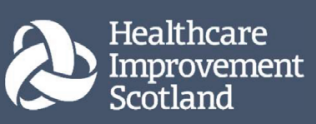

https://www.gov.scot/publications/the-scottishapproach-to-service-design/

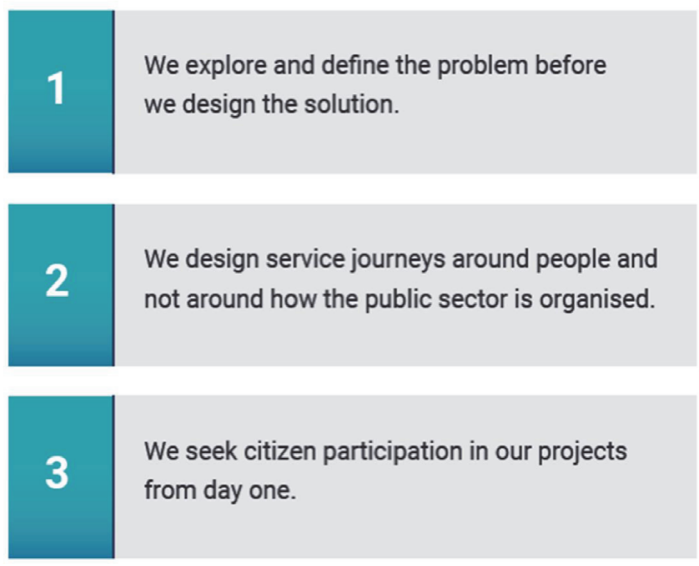

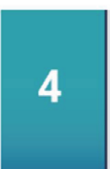

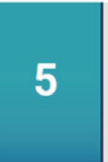

6

We share and reuse user research insights, service patterns, and components wherever possible.

We contribute to continually building the tools, and community.

Abstract 11 Figure 5 